\title{
Development and Validation of a High Performance Thin Layer Chromatographic Method for Quantitative Analysis of Saxagliptin
}

\author{
Salvala Srividya, Ettireddy Swetha, Ciddi Veeresham* \\ University College of Pharmaceutical Sciences, Kakatiya University, Warangal, India \\ Email: ${ }^{*}$ ciddiveeresham@yahoo.co.in
}

Received 17 August 2015; accepted 13 September 2015; published 16 September 2015

Copyright (C) 2015 by authors and Scientific Research Publishing Inc.

This work is licensed under the Creative Commons Attribution International License (CC BY). http://creativecommons.org/licenses/by/4.0/

(c) (i) Open Access

\begin{abstract}
A simple, specific, accurate and precise high performance thin layer chromatographic method (HPTLC) was developed for the quantitative analysis of Saxagliptin in active pharmaceutical ingredients (APIs) and pharmaceutical dosage forms. The method was achieved using silica gel aluminum plate $60 \mathrm{~F}_{254}(10 \times 10 \mathrm{~cm})$ as stationary phase and Methanol:Chloroform $(6: 4 \mathrm{v} / \mathrm{v})$ as mobile phase. The developed plate was scanned densitometrically using UV $222 \mathrm{~nm}$ wavelength. The $R_{f}$ value of Saxagliptin was found to be $0.50 \pm 0.02$. The developed method was validated according to ICH guidelines. Limit of detection (LOD) and limit of quantification (LOQ) of Saxagliptin by this method were found as $7.96 \mathrm{ng} / \mathrm{spot}$ and $26.54 \mathrm{ng} / \mathrm{spot}$, respectively. The method was found to be sensitive, specific, linear, accurate, precise and robust for the quantitative analysis of Saxagliptin in both APIs and marketed tablet formulation.
\end{abstract}

\section{Keywords}

HPTLC, Saxagliptin, Quantitative Analysis, Stress Induced Degradation, Validation, API

\section{Introduction}

Type 2 diabetes mellitus (T2DM) is a complex disease mainly caused by impaired beta cell function and insulin resistance [1]. It is the most common form of diabetes comprising of $90 \%$ to $95 \%$ of all diabetes cases [2]. Oral antidiabetic drugs, along with diet and exercise, can help to control T2DM-associated hyperglycemia in adults [3]. Dipeptidyl peptidase-4 (DPP-4) inhibitors are a class of oral antidiabetic agents which increase circulating

${ }^{*}$ Corresponding author.

How to cite this paper: Srividya, S., Swetha, E. and Veeresham, C. (2015) Development and Validation of a High Performance Thin Layer Chromatographic Method for Quantitative Analysis of Saxagliptin. American Journal of Analytical Chemistry, 6, 797-806. http://dx.doi.org/10.4236/ajac.2015.610076 
concentrations of the incretin gastrointestinal hormones, glucagon-like peptide-1 and glucose-dependent insulinotropic polypeptide. The incretins are rapidly released after meals and stimulate glucose-dependent insulin secretion. Glucagon-like peptide-1 also inhibits glucagon secretion, thereby attenuating postprandial glucose excursions. The DPP-4 inhibitors improve glycaemic control by blocking the rapid inactivation of incretins, mainly glucagon-like peptide-1 [4]. All the DPP-4 inhibitors are orally available and are rapidly absorbed. Within 5 min of administration, they exhibit significant inhibition of plasma DPP-4 activity [5]. Saxagliptin is an oral anti-hypoglycemic agent and it belongs to selective dipeptidyl peptidase-4 (DPP-4) inhibitor class [6]. It is chemically known as (1s,3s,5s)-2-[(2s)-2-amino-2-(3-hydroxy-1-adamantyl) acetyl]-2-azabicyclohexane-3-carbonitrile [7]. Saxagliptin has been shown to be beneficial in glucose management as well as in the achievement of glycated hemoglobin goals (HbA1c $<7 \%$ ) [1].

Several analytical methods have been developed for quantitative analysis of Saxagliptin in bulk and pharmaceutical formulations like UV-spectrophotometric method [8], ion-pairing spectrophotometric method [9], Reverse Phase-High Performance Liquid Chromatography (RP-HPLC) method [10], RP-HPLC with fluorescence detection method [11], etc. Ultra performance liquid chromatography/tandem mass spectrometry (UPLC-MS/MS) method has been developed for quantification of Saxagliptin in rat plasma [12]. Liquid chromatography and tandem mass spectrometry (LC-MS/MS) method has been developed and validated for simultaneous analysis of Saxagliptin and its major metabolite [13]. However, so far there are no reports on High Performance Thin Layer Chromatographic method for quantitative analysis of Saxagliptin in both active pharmaceutical ingredients (APIs) and marketed tablet formulation. Hence the present study was focused for the development and validation of an efficient HPTLC method for the estimation of Saxagliptin.

\section{Materials and Methods}

\subsection{Chemicals and Drugs}

Saxagliptin (API) was obtained as a gift sample from Mylan laboratories Ltd. (Hyderabad, India). Onglyza (Saxagliptin-5 mg) tablets were purchased from Bristol-Myers Squibb (USA). Solvents like Chloroform and Methanol were purchased from SD fine chemicals Ltd. (Mumbai, India).

\subsection{Equipment}

It consists of an applicator of model LINOMAT-5 and a scanner (CAMAG, Switzerland) with UV detector. The data was monitored and processed using WINCAT software. The sample was loaded on to the TLC plates by Hamilton Rheodyne injector syringe of $100 \mu \mathrm{L}$ (CAMAG) and the plate was developed in twin trough chamber $(20 \times 20)$.

\subsection{Standard Solution Preparation}

Standard stock solution was prepared by dissolving $10 \mathrm{mg}$ of Saxagliptin in $100 \mathrm{~mL}$ of methanol to obtain a solution with final concentration, $100 \mu \mathrm{g} / \mathrm{mL}$.

\subsection{Sample Preparation}

Ten tablets of ONGLYZA were weighed and finely powdered. An accurately weighed powder equivalent to 10 mg was taken to $100 \mathrm{~mL}$ volumetric flask and dissolved in $50 \mathrm{~mL}$ Methanol and finally volume was made up to the mark with the Methanol to obtain a concentration of $100 \mu \mathrm{g} / \mathrm{mL}$. This solution was sonicated for $10 \mathrm{~min}$ and filtered. Filtration is done to remove the excipients and to avoid clogging of sample applicator syringe.

\section{Development of a Method}

For the optimization of an HPTLC method, several mobile phase compositions were tried as developing solvent systems, they are shown in Table 1.

\section{Method Validation}

The developed method was validated for various parameters like linearity, limit of detection (LOD), limit of quantification (LOQ), accuracy, precision and robustness according to ICH guidelines. 
Table 1. Optimization of mobile phase.

\begin{tabular}{|c|c|c|c|}
\hline \multirow{2}{*}{ S. No. } & \multicolumn{2}{|c|}{ Mobile Phase Used } & \multirow[t]{2}{*}{ Observation } \\
\hline & Solvents & Ratios & \\
\hline 1 & Butanol:Ethanol:Water & $8: 7: 4$ & No spots \\
\hline 2 & Butanol:Glacial acetic acid:Water & $9.5: 0.2: 0.3$ & Tailing \\
\hline 3 & Chloroform:Ethanol:Water & $8: 1: 1$ & No spots \\
\hline 4 & Methanol:Acetonitrile & $7: 3$ & Spots obtained but not resolved properly \\
\hline 5 & Methanol:Chloroform & $7: 3$ & No tailing \\
\hline 6 & Methanol:Chloroform & $6: 4$ & Well defined spots \\
\hline
\end{tabular}

\subsection{Linearity}

Different concentration solutions of Saxagliptin like 400, 600, 800, 1000 and $1200 \mathrm{ng} / \mathrm{spot}$ were applied on the TLC plate from the standard stock solution. After the development the TLC plate was scanned under UV at 222 $\mathrm{nm}$ and the peaks were recorded using WINCATS software version 1.4.3. The calibration curve was obtained by plotting peak area vs. concentration, using linear regression model. According to ICH guidelines, an acceptance criterion of linearity for an analytical method is correlation coefficient should be not less than 0.998 .

\subsection{LOD and LOQ}

The limit of detection (LOD) and limit of quantification (LOQ) of Saxagliptin by the developed HPTLC method were calculated using the following formulae, respectively.

$$
\mathrm{LOD}=3.3 \sigma / \mathrm{S}
$$

where $\sigma$ is the standard deviation of the response and $S$ is the slope of the calibration curve.

$$
\mathrm{LOQ}=10 \sigma / S
$$

where $\sigma$ is the standard deviation of the response and $S$ is the slope of the calibration curve.

\subsection{Accuracy}

Accuracy is calculated as the percentage of recovery by the assay of known added amount of analyte in the sample, or as the difference between the mean and the accepted true value, together with the confidence intervals. As per ICH guidelines accuracy should be assessed using a minimum of nine determinations i.e., three replicates at three concentrations across the specified range of the procedure. Three different levels $(50 \%, 100 \%$ and $150 \%$ ) of standard solutions were added to a pre-analyzed sample and were analyzed for \% recovery of Saxagliptin. Acceptance criterion is the mean \% recovery should not be less than $98 \%$ and not more than $102 \%$.

\subsection{Precision}

ICH guidelines recommend that repeatability should be assessed using a minimum of nine determinations covering the specified range of the procedure (i.e., three replicates of three concentrations) or using a minimum of six determinations at $100 \%$ of the test concentration. It can be determined by measuring repeatability, intermediate precision and reproducibility. Three different concentration solutions of standard Saxagliptin were applied to the TLC plate and the chromatograms were recorded. The precision of an analytical procedure is usually expressed as the variance, standard deviation or coefficient of variation of a series of measurements and the acceptance criterion is \% RSD of the peak areas should not be more than $2.0 \%$.

\subsection{Robustness}

The robustness of an analytical method is a measure of its capacity to remain unaffected by small but deliberate variations in method parameters and provides an indication of its reliability during normal usage. It was done by 
changing the mobile phase volume and development time while constantly maintaining the remaining parameters. The acceptance criterion is \% RSD of the peak areas should not be more than $2.0 \%$.

\section{Stability Studies}

To evaluate the stability indicating properties of the developed HPTLC method, forced degradation studies were carried out in accordance to the ICH guidelines and were performed by exposing drug solution to stress conditions like acidic $(0.1 \mathrm{~N} \mathrm{HCl}, 1 \mathrm{~N} \mathrm{HCl})$, basic $(0.1 \mathrm{~N} \mathrm{NaOH}, 1 \mathrm{~N} \mathrm{NaOH})$, peroxide $\left(3 \% \mathrm{H}_{2} \mathrm{O}_{2} \mathrm{v} / \mathrm{v}\right)$ and photo induced degradation. The resulting solutions were analyzed for analyte peak and unknown degradants generated by stress induced degradation.

\section{Results and Discussion}

\subsection{Optimization of HPTLC Method for Quantitative Analysis of Saxagliptin}

After multiple trials an optimized mobile phase was developed for the HPTLC analysis of Saxagliptin. The standard and test samples were spotted in the form of bands of width $8 \mathrm{~mm}$ using a $100 \mu \mathrm{L}$ syringe on precoated silica gel aluminum plate $60 \mathrm{~F}_{254}(10 \times 10 \mathrm{~cm})$ using a CAMAG Linomat-5 sample applicator. The development was carried out in $20 \times 20 \mathrm{~cm}$ twin trough glass chamber using Methanol:Chloroform (6:4 v/v) as mobile phase. The saturation time for mobile phase was $20 \mathrm{~min}$. The development time was 20 to 30 minutes. After the development, the TLC plates were air dried and were densitometrically scanned using CAMAG thin layer chromatographic scanner at $222 \mathrm{~nm}$. The chromatograms were recorded using WINCATS software version 1.4.3. The chromatogram of Saxagliptin is shown in Figure 1. This method has shown good resolution of Saxagliptin in both standard and test samples and the $\mathrm{R}_{\mathrm{f}}$ value was found to be $0.50 \pm 0.02$.

\subsection{Assay of Saxagliptin in Formulation}

The chromatograms of standard as well as test Saxagliptin solutions were recorded and the percentage of drug content was calculated. The percentage assay for Saxagliptin was found to be $98.90 \%$, which lies within the limits mentioned by ICH (98\% - 120\%). Hence the developed method can be routinely used for the estimation of Saxagliptin in the tablet formulations. The chromatogram of Saxagliptin test solution (sample solution) was shown in Figure 2.

\subsection{Method Validation}

\subsubsection{Linearity}

Calibration curve of Saxagliptin was plotted using peak area vs. concentration and was shown in Figure 3.

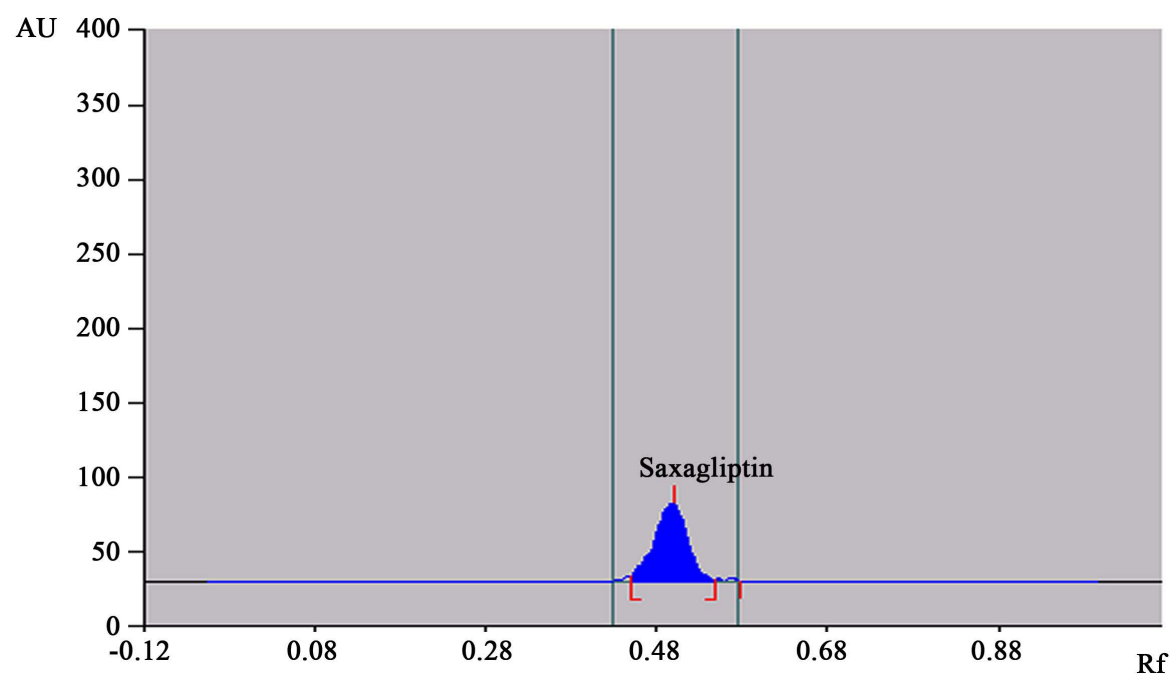

Figure 1. Chromatogram of standard Saxagliptin (800 ng/spot). 


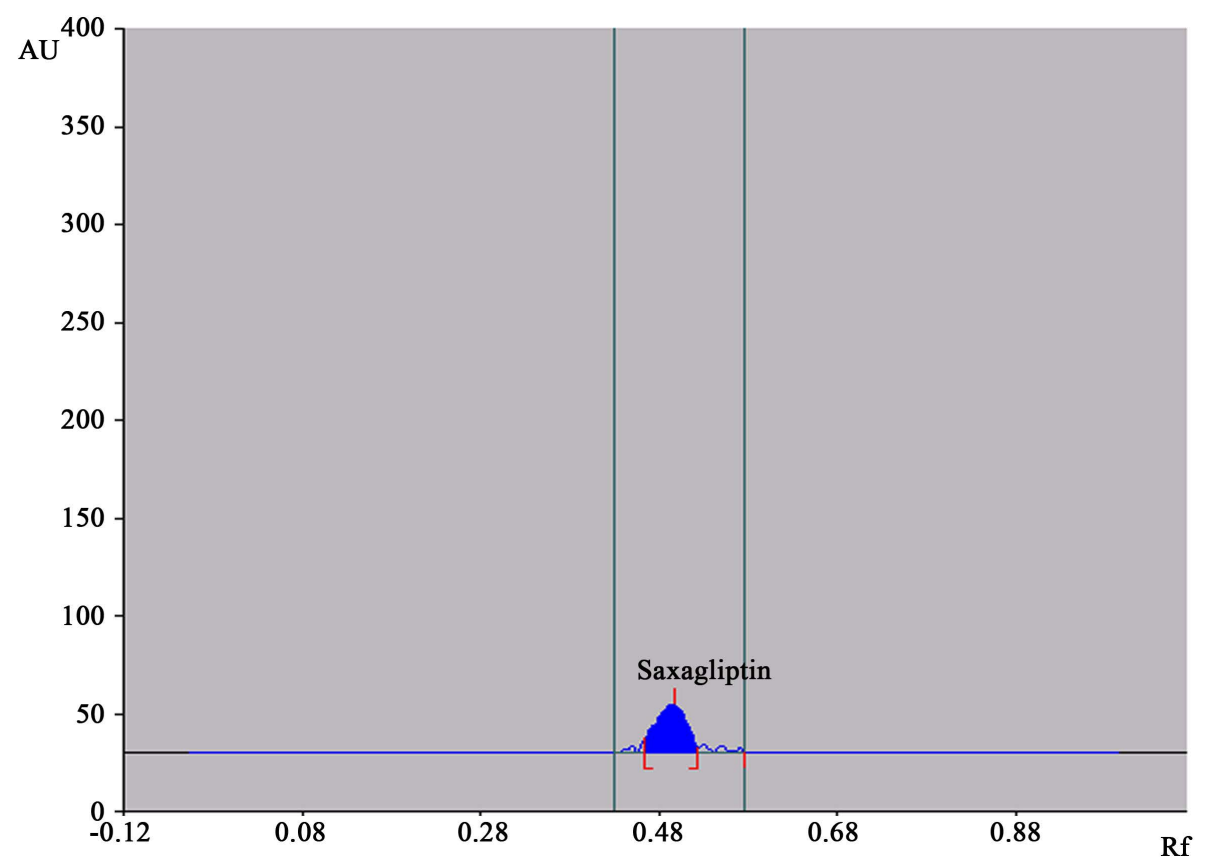

Figure 2. Chromatogram of Saxagliptin test solution (800 ng/spot).

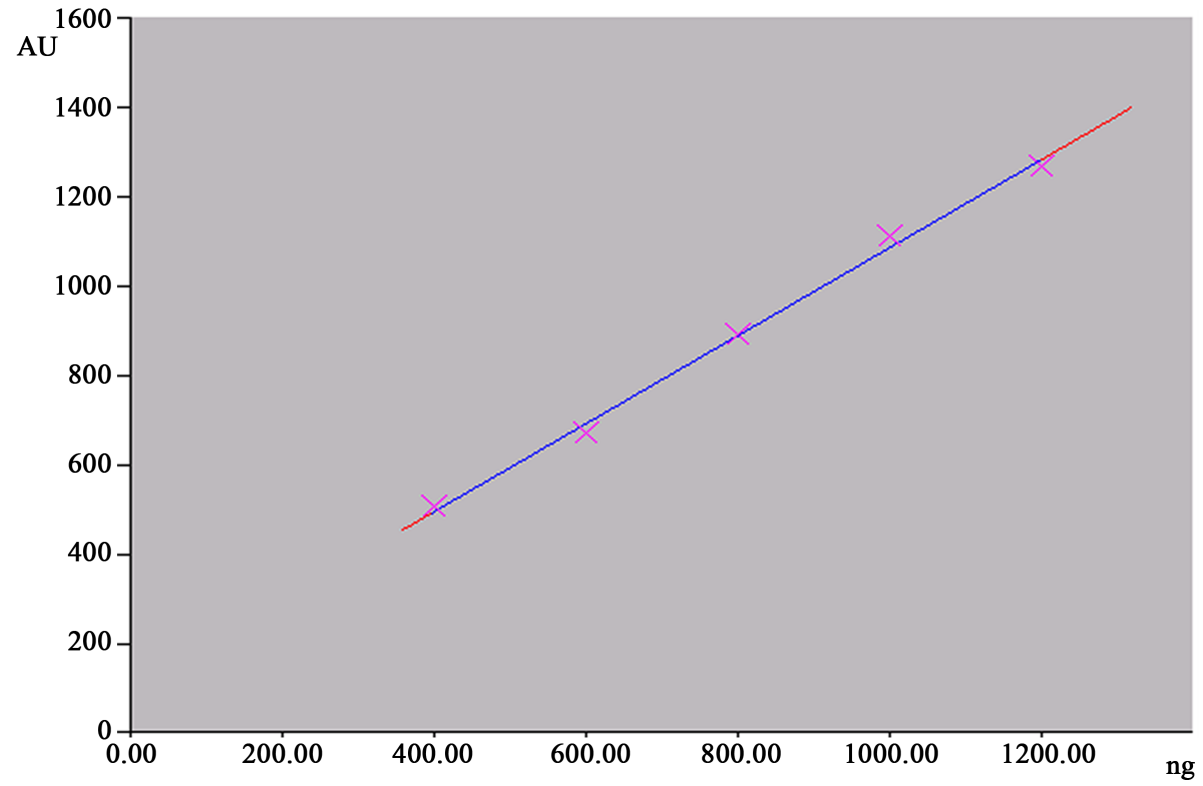

Figure 3. Calibration curve of Saxagliptin.

Linearity was found in the concentration range of 400 - $1200 \mathrm{ng} / \mathrm{spot}$, which was shown by a 3D display in Figure 4. Saxagliptin correlation coefficient value was found to be 0.998 . As per ICH guidelines, it lies in acceptable limit and hence the method was found to be linear.

\subsubsection{LOD and LOQ}

The lowest possible concentration of Saxagliptin that can be detected and quantified by the present method was found to be $7.96 \mathrm{ng} / \mathrm{spot}$ and $26.54 \mathrm{ng} / \mathrm{spot}$, respectively. The low values of LOD and LOQ indicates that the method can be used for detection and quantification of Saxagliptin over a very wide range of concentrations in formulations. 


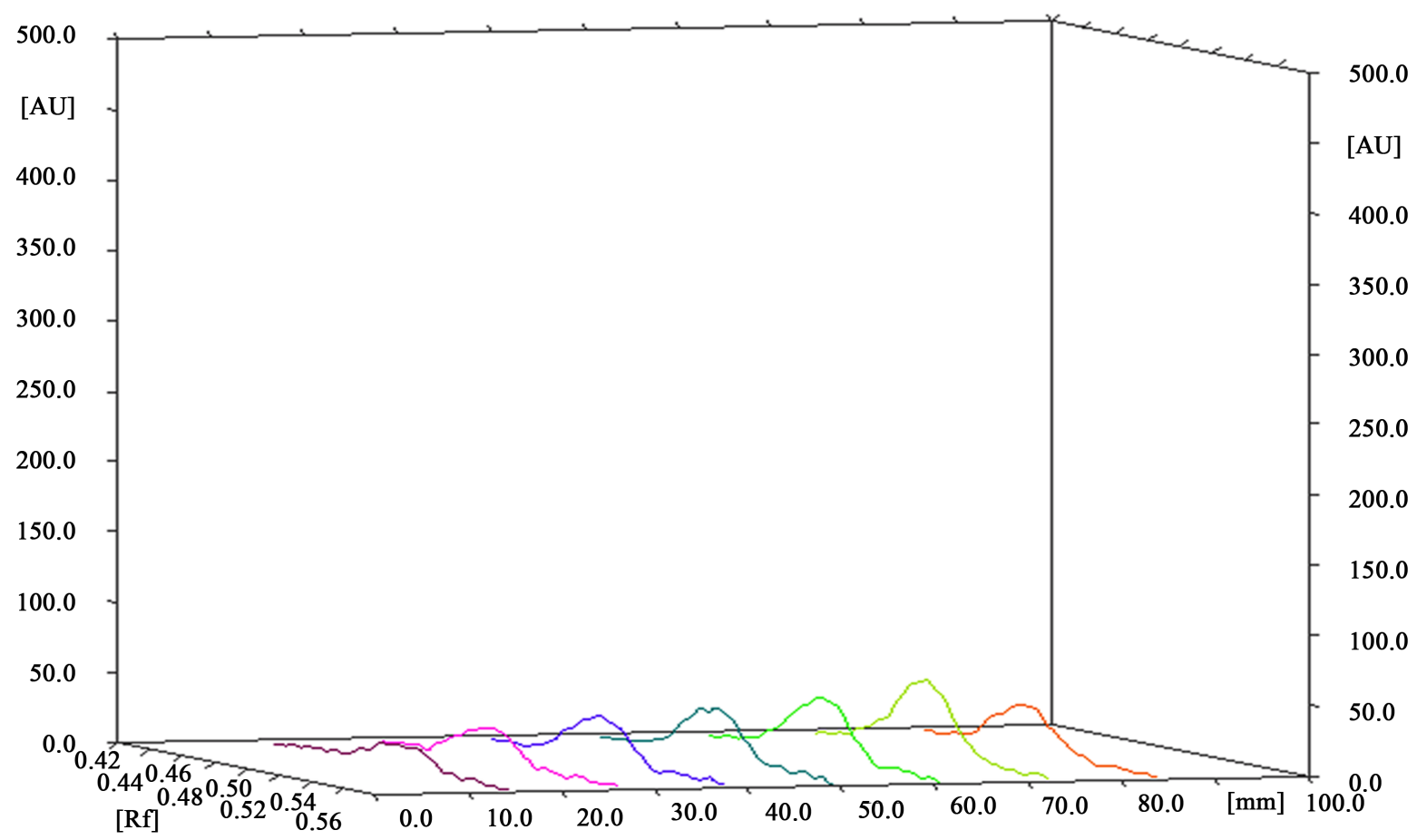

Figure 4. 3D display of Saxagliptin linearity.

\subsubsection{Accuracy}

Mean percentage recovery values at three different concentrations of Saxagliptin were calculated and the results were shown in Table 2. According to ICH guidelines, the \% recovery of Saxagliptin at each level was within the limits of $98 \%$ to $102 \%$. Hence, the method was proved to be accurate.

\subsubsection{Precision}

Intra-day and Inter-day precision data of Saxagliptin was shown in Table 3. \% RSD values of Saxagliptin in both intra- and inter-day precision studies were found to be less than 2, which were within the limits mentioned by ICH guidelines. Hence the method was found to be precise.

\subsubsection{Robustness}

Robustness was done by changing the mobile phase volume and saturation time of development chamber. The data is shown in Table 4.

\section{Stability Studies}

The standard drug was subjected to acid, base (alkali), oxidation and photolytic degradation studies and their chromatograms were shown in Figures 5-8. Results of Saxagliptin degradation studies are shown in Table 5. These results revealed the suitability of the method to study stability of Saxagliptin in APIs and pharmaceutical dosage forms.

\section{Conclusion}

The present study was aimed for the development and validation of HPTLC method for the estimation of Saxagliptin in bulk as well as pharmaceutical dosage forms. After performing various trials, a sensitive method was developed and was validated according to ICH guidelines. The method was proved to be sensitive, specific, linear, accurate, precise and robust for the quantitative analysis of Saxagliptin in active pharmaceutical ingredients (APIs) and pharmaceutical dosage forms. It does not suffer from interference from excipients present in 


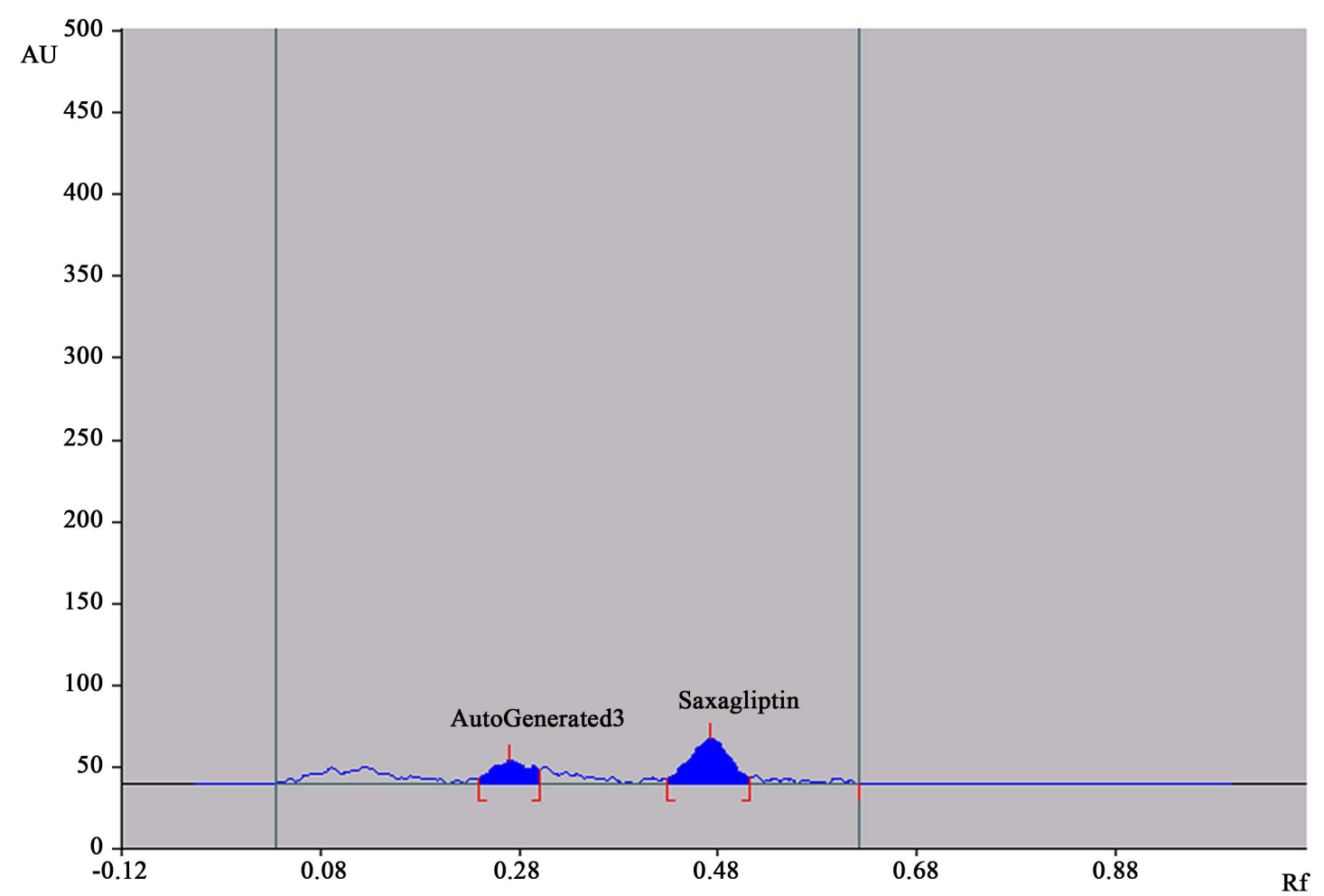

Figure 5. Chromatogram of acid degraded Saxagliptin (800 ng/spot).

Table 2. Accuracy study of Saxagliptin.

\begin{tabular}{|c|c|c|c|c|c|c|}
\hline Recovery level & Sample (ng/spot) & Standard (ng/spot) & Amount found (ng/spot) & \% Recovery & Mean $(\%) \pm S D$ & $\%$ RSD \\
\hline \multirow{3}{*}{$50 \%$} & \multirow{3}{*}{800} & \multirow{3}{*}{400} & 1189.67 & 99.13 & \multirow{3}{*}{$98.17 \pm 0.99$} & \multirow{3}{*}{1.015} \\
\hline & & & 1178.98 & 98.24 & & \\
\hline & & & 1165.76 & 97.14 & & \\
\hline \multirow{3}{*}{$100 \%$} & \multirow{3}{*}{800} & \multirow{3}{*}{800} & 1618.15 & 101.13 & \multirow{3}{*}{$100.50 \pm 0.61$} & \multirow{3}{*}{0.608} \\
\hline & & & 1598.58 & 99.91 & & \\
\hline & & & 1607.45 & 100.46 & & \\
\hline \multirow{3}{*}{$150 \%$} & \multirow{3}{*}{800} & \multirow{3}{*}{1200} & 2016.54 & 100.82 & \multirow{3}{*}{$100.03 \pm 0.71$} & \multirow{3}{*}{0.715} \\
\hline & & & 1988.63 & 99.43 & & \\
\hline & & & 1996.75 & 99.83 & & \\
\hline
\end{tabular}

Table 3. Intra- and inter-day precision study of Saxagliptin.

\begin{tabular}{ccc}
\hline & & \% RSD \\
Concentration (ng/spot) & Intra-day precision & Inter-day precision \\
\cline { 2 - 3 } 600 & 1.124 & 0.748 \\
800 & 0.789 & 0.113 \\
1000 & 0.615 & 0.893 \\
\hline
\end{tabular}




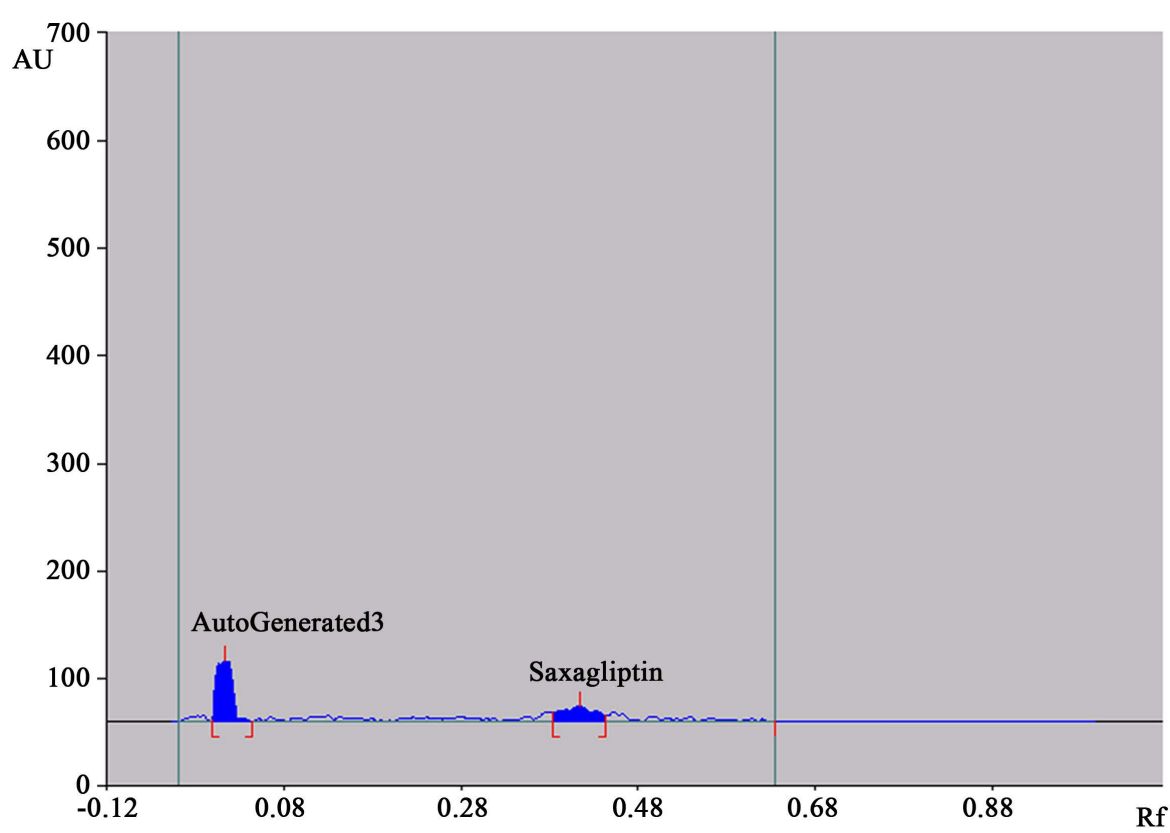

Figure 6. Chromatogram of alkali degraded Saxagliptin (800 ng/spot).

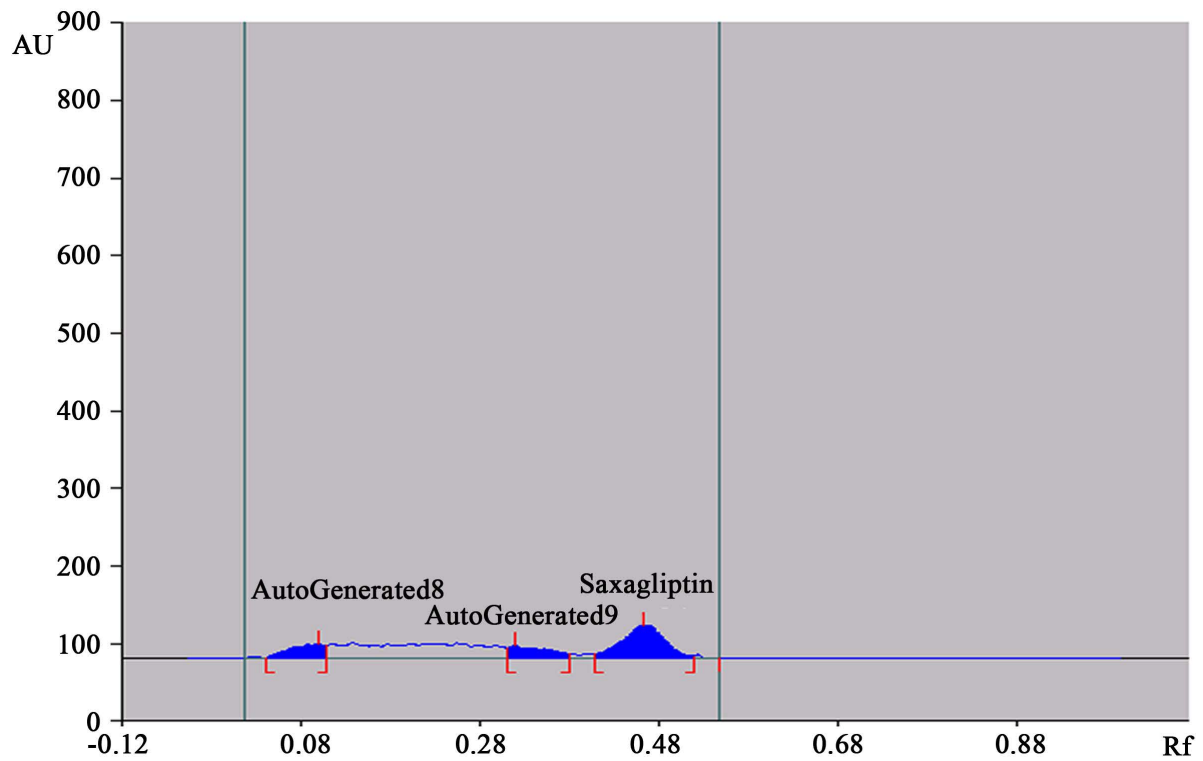

Figure 7. Chromatogram of oxidation degraded Saxagliptin (800 ng/spot).

Table 4. Robustness data of Saxagliptin.

\begin{tabular}{|c|c|c|c|c|c|}
\hline Parameter & Condition opted & Concentration & $\mathrm{R}_{\mathrm{F}}$ & Mean $(\%) \pm$ SD & $\%$ RSD \\
\hline \multirow{3}{*}{ Volume of mobile phase } & $12 \mathrm{~mL}$ & \multirow{3}{*}{800 ng/spot } & 0.53 & $892.78 \pm 2.06$ & 1.014 \\
\hline & $15 \mathrm{~mL}$ & & 0.52 & $881.89 \pm 1.09$ & 0.69 \\
\hline & $18 \mathrm{~mL}$ & & 0.55 & $902.93 \pm 1.57$ & 0.838 \\
\hline \multirow{3}{*}{ Saturation time of development chamber } & $20 \mathrm{~min}$ & \multirow{3}{*}{800 ng/spot } & 0.54 & $876.89 \pm 2.35$ & 0.952 \\
\hline & $30 \mathrm{~min}$ & & 0.50 & $905.21 \pm 1.88$ & 1.090 \\
\hline & $40 \mathrm{~min}$ & & 0.56 & $886.67 \pm 1.45$ & 0.615 \\
\hline
\end{tabular}




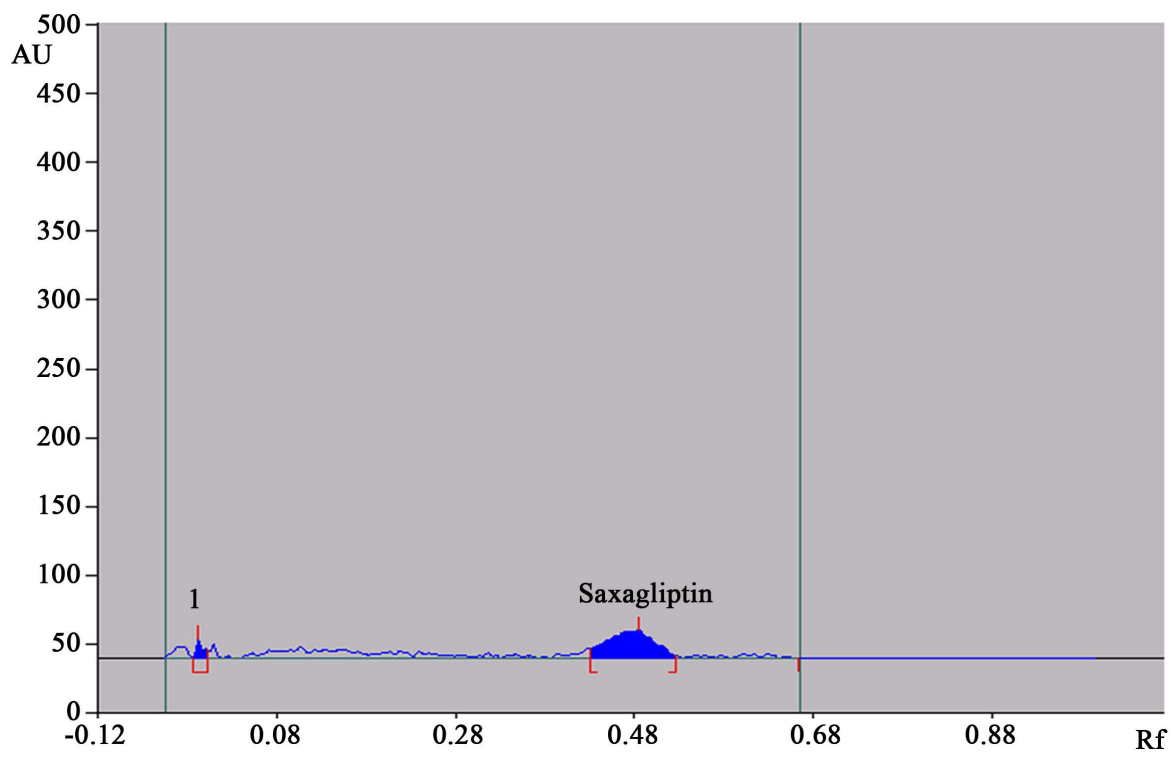

Figure 8. Chromatogram of photolytic degraded Saxagliptin (800 ng/spot).

Table 5. Saxagliptin degradation studies.

\begin{tabular}{ccc}
\hline Stress conditions applied for Saxagliptin $(1000 \mathrm{ng} / \mathrm{spot})$ & Time $(\mathrm{h})$ & \% of active drug present after degradation \pm SD \\
\hline Acid $\left(\mathrm{HCl} 0.1 \mathrm{~N} ; 80^{\circ} \mathrm{C}\right)$ & 1 & $78.65 \pm 1.72$ \\
Acid $\left(\mathrm{HCl} 1 \mathrm{~N} ; 80^{\circ} \mathrm{C}\right)$ & 1 & $75.23 \pm 1.53$ \\
Alkali $\left(\mathrm{NaOH} 0.1 \mathrm{~N} ; 80^{\circ} \mathrm{C}\right)$ & 1 & $37.08 \pm 0.97$ \\
Alkali $\left(\mathrm{NaOH} 1 \mathrm{~N} ; 80^{\circ} \mathrm{C}\right)$ & 1 & $34.71 \pm 1.35$ \\
$3 \% \mathrm{H}_{2} \mathrm{O}_{2}$ & 1 & $70.18 \pm 1.03$ \\
Photolytic degradation (Sunlight) & 24 & $91.65 \pm 1.46$ \\
\hline
\end{tabular}

the pharmaceutical dosage forms as well as from the degradants of Saxagliptin resulted from stress-induced degradation studies. Hence this method can be conveniently adopted for quality control analysis and stability assays of Saxagliptin in APIs and pharmaceutical dosage forms.

\section{Acknowledgements}

The authors are thankful to Mylan laboratories Ltd. (Hyderabad, India) for the kind gift of Saxagliptin Active Pharmaceutical Ingredient (API).

\section{References}

[1] Li, C.J., Liu, X.J., Bai, L., Yu, Q., Zhang, Q.M., Yu, P. and Yu, D.M. (2014) Efficacy and Safety of Vildagliptin, Saxagliptin or Sitagliptin as Add-On Therapy in Chinese Patients with Type 2 Diabetes Inadequately Controlled with Dual Combination of Traditional Oral Hypoglycemic Agents. Diabetology \& Metabolic Syndrome, 6, 1-9. http://dx.doi.org/10.1186/1758-5996-6-69

[2] Qaseem, A., Linda, L.H., Donna, E.S., Melissa, S. and Paul, S. (2012) Oral Pharmacologic Treatment of Type 2 Diabetes Mellitus: A Clinical Practice Guideline from the American College of Physicians. Annals of Internal Medicine, 156, 218-231. http://dx.doi.org/10.7326/0003-4819-156-3-201202070-00011

[3] Saine, M.E., Carbonari, D.M., Newcomb, C.W., Melissa, S.N., Kevin, H., Vincent, L.R., et al. (2015) Determinants of Saxagliptin Use among Patients with Type 2 Diabetes Mellitus Treated with Oral Anti-Diabetic Drugs. BMC Pharmacology and Toxicology, 16, 1-16. http://dx.doi.org/10.1186/s40360-015-0007-z

[4] Scheen, A.J., Charpentier, G., Östgren, C.J., Hellqvist, A. and Gause-Nilsson, I. (2010) Efficacy and Safety of Saxag- 
liptin in Combination with Metformin Compared with Sitagliptin in Combination with Metformin in Adult Patients with Type 2 Diabetes Mellitus. Diabetes Metabolism Research and Reviews, 26, 540-549. http://dx.doi.org/10.1002/dmrr.1114

[5] Deacon, C.F. (2011) Dipeptidyl Peptidase-4 Inhibitors in the Treatment of Type 2 Diabetes: A Comparative Review. Diabetes, Obesity and Metabolism, 13, 7-18. http://dx.doi.org/10.1111/j.1463-1326.2010.01306.x

[6] Michael, E.C. and Robert, F. (2012) Saxagliptin for the Treatment of Type 2 Diabetes Mellitus: Assessing Cardiovascular Data. Cardiovascular Diabetology, 11, 1-8.

[7] Sravana Kumara, K. and Sailaja, B. (2015) Analytical Method Development and Validation for Estimation of Dipeptidyl Peptidase-4 Inhibitors: A Review. International Journal of Current Research in Chemistry and Pharmaceutical Sciences, 2, 83-98.

[8] Kalaichelvi, R. and Jayachandran, E. (2011) Validated Spectroscopic Method for estimation of Saxagliptin in Pure and from Tablet Formulation. International Journal of Pharmacy and Pharmaceutical Sciences, 3, 179-180.

[9] Ramalingam, K. and Jayachandran, E. (2012) Extractive Spectrophotometric Estimation of Saxagliptin in Pure and in Pharmaceutical Dosage Form. American Journal of Pharma Tech Research, 2, 429-433.

[10] Serife, E.K.T., Mustafa, V.K. and Demet, D. (2013) An HPLC Method for the Determination of Saxagliptin in Human Plasma with Fluorescence Detection. Journal of Advances in Chemistry, 3, 810-818.

[11] Vaishali, V. and Anand Kumara, D. (2013) Development and Validation of a Liquid Chromatographic Method for Estimation of Saxagliptin in Tablet Dosage Form. Asian Journal of Research in Chemistry, 6, 552-554.

[12] Gao, J., Yuan, Y., Lu, Y. and Yao, M. (2012) Development of A rapid UPLC-MS/MS Method for Quantification of Saxagliptin in Rat Plasma and Application to Pharmacokinetic Study. Biomed Chromatography, 26, 1482-1487. http://dx.doi.org/10.1002/bmc.2720

[13] Xiaohui, X., Roger, D., Huidong, G., Lisa, J., Christophera, H.S., Laura, C., et al. (2012) Liquid Chromatography and Tandem Mass Spectrometry Method for the Quantitative Determination of Saxagliptin and Its Major Pharmacologically Active 5-Monohydroxy Metabolite in Human Plasma: Method Validation and Overcoming Specific and Non-Specific Binding at Low Concentrations. Journal of Chromatography B, 889-890, 77-86.

http://dx.doi.org/10.1016/j.jchromb.2012.01.033 